\title{
Ocorrência de doença infundibular, sobremordida e ganchos em equinos de cavalaria militar
}

[Infundibular disease, over-bite, and dental hooks occurrence in military horses]

\author{
J.T.M. Lima ${ }^{1}$, B.S.C. Andrade ${ }^{2}$, S.V. Schwarzbach ${ }^{3}$, C.A. De Marval ${ }^{4}$, B.B. Leal ${ }^{5}$, \\ R.R. Faleiros ${ }^{6}$, G.E.S. Alves ${ }^{6}$
}

\author{
${ }^{1}$ Aluna de graduação - EV-UFMG - Belo Horizonte, MG \\ ${ }^{2}$ Aluno de pós-graduação - EV-UFMG - Belo Horizonte, MG \\ ${ }^{3}$ UNICENTRO - Guarapuava, PR \\ ${ }^{4}$ Ten. Médico Veterinário - PMMG - Belo Horizonte, MG \\ ${ }^{5}$ Aluno de pós-graduação - PUC-Minas - Betim, MG \\ ${ }^{6}$ Escola de Veterinária - UFMG - Belo Horizonte, MG
}

\begin{abstract}
RESUMO
Avaliou-se a ocorrência da doença infundibular (DI) e a associação entre sobremordida (SM) e ganchos dentários rostral e caudal da maxila e mandíbula. Utilizaram-se 88 equinos - 52 machos e 36 fêmeas -, entre três e 27 anos. Para os exames odontológicos, os animais foram contidos em brete e sedados com xilazina $10 \%$ a $0,5 \mathrm{mg} / \mathrm{kg}$ IV e utilizaram-se abridor de boca, fotóforo elétrico e sonda odontológica de aço inox. Agruparam-se os equinos por idade. O grupo 1 foi formado por animais até nove anos; o G2 de 10 a 14 e G3 de 15 a 27 anos. Foi diagnosticada DI em (37,5\%) animais, nos dentes molares e prémolares. A incidência maior de DI foi nos dentes 109 (11,4\%) e 209 (12,5\%). Houve correlação positiva entre a idade e o número de dentes acometidos $(\mathrm{r}=0,26 ; \mathrm{P}<0,02)$. A maior ocorrência de DI no grupo mais acometido (G3) foi nos dentes 108 e 208. Verificaram-se 66\% de SM e 65\% de ganchos. Observou-se correlação entre $\mathrm{SM}$ e presença total de ganchos $(\mathrm{r}=0,26, \mathrm{P}=0,016)$, entre $\mathrm{SM}$ e ganchos rostrais maxilares e mandibulares $(\mathrm{r}=0,25, \mathrm{P}=0,016)$ e ganchos rostrais maxilares $(\mathrm{r}=0,24, \mathrm{P}=0,02)$. Animais com ganchos pré-molares maxilares tiveram 2,8 vezes mais chance de apresentarem SM (IC 95\% = 1,1 a 7,1).
\end{abstract}

Palavras-chave: equino, doença infundibular, sobremordida, gancho

\begin{abstract}
The occurrence of infundibular disease (ID) and the association between over-bite (OB) and rostral and caudal hooks on teeth of the maxilla and jaw were evaluated in 88 horses - 52 males and 36 females aging from between 3 and 27 years old. The horses were restrained in stocks, sedated with xylazine and examined using a mouth-speculum and a stainless steel pick. The data were recorded on individual charts. The animals were grouped by age: group 1: 3 to 9, group 2: 10 to 14, and group 3: 15 to 27 years old. ID was identified on the premolar and molar teeth in $37.5 \%$ of horses. There was a positive correlation between age and number of affected teeth $(r=0.26, P<0.02)$. The most affected teeth were the 109 (11.4\%) and 209 (12.5\%). The highest occurrence of ID in the most affected group (G3) was on the 108 and 208 teeth. There were $66 \%$ of $\mathrm{OB}$ and $65 \%$ of hooks. There was a correlation between $\mathrm{OB}$ and the presence of total $(r=0.26, P=0.016)$, maxillary and mandibular $(r=0.25, P=0.016)$, and maxillary rostral hooks $(r=0.24, P=0.02)$. Only the association between $O B$ and maxillary rostral hooks was significant. Animals with maxillary pre-molars hooks were 2.8 times predisposed to have OB (CI $95 \%=1.1$ to 7.1 ).
\end{abstract}

Keywords: horse, infundibular disease, over-bite, hook

Recebido em 20 de fevereiro de 2010

Aceito em 22 de dezembro de 2010

E-mail: julia.timponi@gmail.com 


\section{INTRODUÇÃO}

O exame e o tratamento odontológico periódicos nos equinos são fundamentais para garantir a manutenção da sanidade dentária e o aproveitamento adequado do alimento ingerido. A correção de anormalidades dentárias, como pontas excessivas de esmalte e ganchos, pode resultar em maior eficiência na mastigação dos alimentos, no ganho de peso e na redução da incidência de cólica por impactação e obstrução intestinal (Ralston, 2005).

A oferta em excesso de concentrados e forragens tenras e pouco variadas, associada ao confinamento, são fatores que contribuem para ocorrência de afecções dentárias (Pagliosa et al., 2006). Entre essas afecções, encontram-se a doença infundibular (DI), a sobremordida e os ganchos.

A DI é uma bacteriose necrosante, que afeta prémolares e molares maxilares. A afecção é pouco observada nos incisivos, com maior incidência em equinos idosos (Johnson e Porter, 2006). Os pré-molares e molares maxilares possuem invaginações do esmalte, denominadas infundíbulos, que são preenchidas por cemento (Jonhson e Porter, 2006) e que têm como função aumentar a superfície de contato e o atrito, de modo a otimizar a eficiência mastigatória (Baker e Easley, 2005). O fator predisponente principal à DI é a hipoplasia do cemento que resulta em preenchimento incompleto do infundíbulo. Kilic et al. (1997) diagnosticaram DI em 24\% dos dentes examinados, e $65 \%$ dos dentes examinados continham áreas de hipoplasia do cemento. A hipoplasia do cemento favorece o acúmulo de alimentos, bactérias, produção de ácidos por fermentação e reações enzimáticas que corroem os tecidos dentários (Crabill e Schumacher, 1998; Johnson e Porter, 2006). Por ação ácida, há comprometimento da calcificação, dissolução da parte inorgânica do dente e desintegração da parte orgânica (Baker, 1974). Tais ocorrências são agravadas pela maior utilização de alimentos de natureza concentrada ricos em cereais, levando à diminuição da eficiência da autolimpeza do infundíbulo, o que cria condições propícias para o desenvolvimento de microrganismos (Baker e Easley, 2005).

O gancho dentário forma-se pela falta de desgaste em uma área rostral ou caudal dos dentes, resultando em contato oclusal incompleto. São mais frequentes na face rostral dos segundos pré-molares maxilares (106 e 206) e na caudal dos terceiros molares mandibulares (311 e 411) (Baker e Easley, 2005; Pagliosa et al., 2006). A ocorrência de gancho pode ter relação com o confinamento, pois nesse manejo o alimento é disponibilizado acima do nível do solo, diferente do hábito natural de ingestão de alimentos dos equinos. A altura elevada na qual os alimentos são oferecidos pode, progressivamente, prejudicar os movimentos mastigatórios rostro-caudais. Além disso, alimentos à base de ração concentrada estimulam a movimentação vertical, alterando, também, a forma de desgaste dos dentes (Pagliosa et al., 2006). Como consequência da presença de gancho, pode ocorrer compressão periodontal e da coroa de reserva, podendo causar reabsorção do osso alveolar. Posteriormente, tal processo pode levar à formação de diastemas (espaços interdentários), com consequente acúmulo de alimentos, seguido de inflamação e infecção nesses espaços e favorecendo a doença periodontal e a perda dentária (Baker e Easley, 2005).

A sobremordida (SM) é um distúrbio parcial de oclusão, no qual os dentes incisivos maxilares apresentam-se rostrais aos mandibulares. Segundo Dixon e Dacre (2005), o maior significado clínico da ocorrência de sobremordida é o fato de ela estar usualmente associada a alterações nos dentes pré-molares e molares. Com a ocorrência de SM, os prémolares e molares superiores ficam posicionados rostralmente aos dentes correspondentes da arcada inferior. Com isso, há o crescimento irregular da parte rostral dos pré-molares superiores 106 e 206 e da parte caudal dos molares inferiores 311 e 411, levando à formação de ganchos dentários. No entanto, outras etiologias também foram sugeridas para esse distúrbio, tais como desequilíbrio entre o desenvolvimento da maxila e da mandíbula, ou trauma na região temporomandibular (Crabill e Schumacher,1998; Dixon et al., 1999).

Este estudo teve como objetivo avaliar a prevalência de DI em equinos da cavalaria militar de Minas Gerais. Nos mesmos animais, determinou-se a ocorrência de sobremordida, ganchos e suas possíveis associações. 


\section{MATERIAL E MÉTODOS}

Examinaram-se as cavidades orais de 88 equinos - 52 machos e 36 fêmeas -, da raça Brasileiro de Hipismo ou mestiços, idade entre três e 27 anos e escore corporal entre 3 e 4 segundo Spiers (1997). Os animais pertenciam à cavalaria militar, onde eram manejados e recebiam $6 \mathrm{~kg}$ de ração comercial (1,2\% do PV/dia), divididos em porções iguais, quatro vezes ao dia. Também recebiam de 6 a $8 \mathrm{~kg}$ de feno de coast-cross, divididos em porções iguais, três vezes ao dia. O fornecimento das porções de volumoso e concentrado era intercalado. Essa distribuição das refeições foi feita com o objetivo de prolongar o tempo de alimentação dos equinos, por dia.

Os exames odontológicos foram realizados por, no mínimo, dois veterinários e três graduandos de medicina veterinária. Após o jejum de 12h, os animais foram contidos em brete e sedados com xilazina $\quad 10 \% \quad(0,5 \mathrm{mg} / \mathrm{kg} / \mathrm{IV}) . \quad \mathrm{O}$ exame odontológico foi por inspeção da cavidade oral, utilizando-se um abre-bocas modelo Haussman, um fotóforo elétrico e sondas de aço inox de $44,5 \mathrm{~cm}$, após a cavidade oral ser lavada, usandose tubo de plástico conduzindo água.

DI, SM e ganchos dentários foram diagnosticados referindo-se os dentes pelo método de Triadan utilizado por Omura (2003), sendo os registros feitos em prontuários individuais. As principais alterações foram registradas, também, por fotografias.

A SM foi avaliada antes de o equino ser sedado e com a cabeça em posição neutra, ou seja, a posição que o animal adota quando está em estação e mastigando (Gordon, 1998). Os lábios inferior e superior foram afastados para a visualização dos incisivos. Em seguida, o grau de SM foi avaliado de 0 a 3, sendo que 0 : é ausência de SM; 1: é visualização parcial da mesa dentária, mas sem visualização do infundíbulo dos incisivos 101 e 201; 2: é presença de SM com visualização parcial da mesa dentária e do infundíbulo dos dentes 101 e 201 e 3: é visualização completa da mesa dentária dos dentes 101 e 201.

Para verificar possível influência da idade na ocorrência da DI, os animais foram separados em grupos: o G1 foi formado por animais com até nove anos; o G2 por animais de 10 a 14 anos; o
G3 por animais de 15 a 27 anos. A associação com a idade foi verificada por teste de correlação, e a dispersão de frequência entre grupos foi avaliada pelo teste qui-quadrado.

Para determinar a associação entre SM e ganchos dentários, utilizou-se o teste de Spearman. Este teste avaliou a correlação entre a presença de SM e duas diferentes ocorrências de ganchos: ganchos rostrais nos dentes pré-molares maxilares, e ganchos caudais nos dentes molares mandibulares, avaliando-se o resultado em conjunto e individualmente para cada dente. Com o mesmo teste, verificou-se também a relação entre sobremordida e ganchos totais. Nos casos em que houve correlação significativa, realizou-se o teste de qui-quadrado, seguido de odds ratio.

\section{RESULTADOS E DISCUSSÃO}

A DI ocorreu em 33 (37,5\%) animais. A localização foi em dentes pré-molares e molares maxilares. Entre os dentes acometidos por DI, os de número 109 e 209 apresentaram incidências de $11,4 \%$ e $12,5 \%$, respectivamente. Tal incidência, elevada, também relatada por Crabill e Schumacher (1998), sugere que, por serem esses dentes os mais antigos nas arcadas e que, portanto, por mais tempo passaram por desgaste da boca e para os quais não há dentição temporária, são mais predispostos para a ocorrência de DI. Nos dentes incisivos, não foi diagnosticada, o que se explica pelas suas particularidades morfológicas e funcionais em relação aos pré-molares e molares (Baker e Easley, 2005).

Houve correlação positiva entre idade e número de dentes acometidos pela doença infundibular $(\mathrm{r}=0,26$ e $\mathrm{P}<0,02)$, demonstrando o aumento da susceptibilidade dos dentes à DI ao decorrer dos anos. Embora fosse notado o predomínio da DI no grupo de animais mais velhos (G3), as incidências da afecção em G1 (38,7\%), em G2 (25,7\%) e em G3 (54,5\%) não demonstraram diferença significativa. Os dentes mais frequentemente acometidos por DI no G3 foram o 208 (Fig. 1) e o 108 (Fig. 2 e 3). Como o número maior de animais acometidos foi do grupo de animais com idade mais avançada, acredita-se que, à medida que avança a idade, ocorre exposição por mais tempo aos fatores que causam DI, o que aumenta as chances de manifestação da doença. 


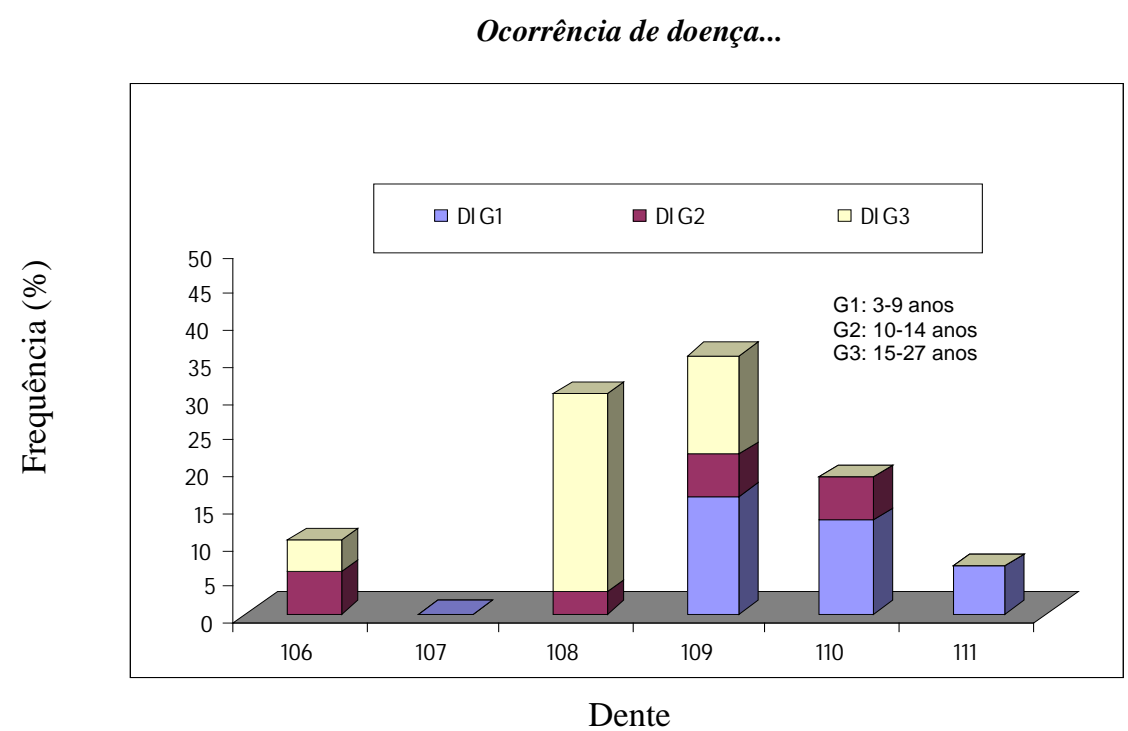

Figura 1. Frequência de doença infundibular (DI) nos dentes da maxila lado direito, em equinos.

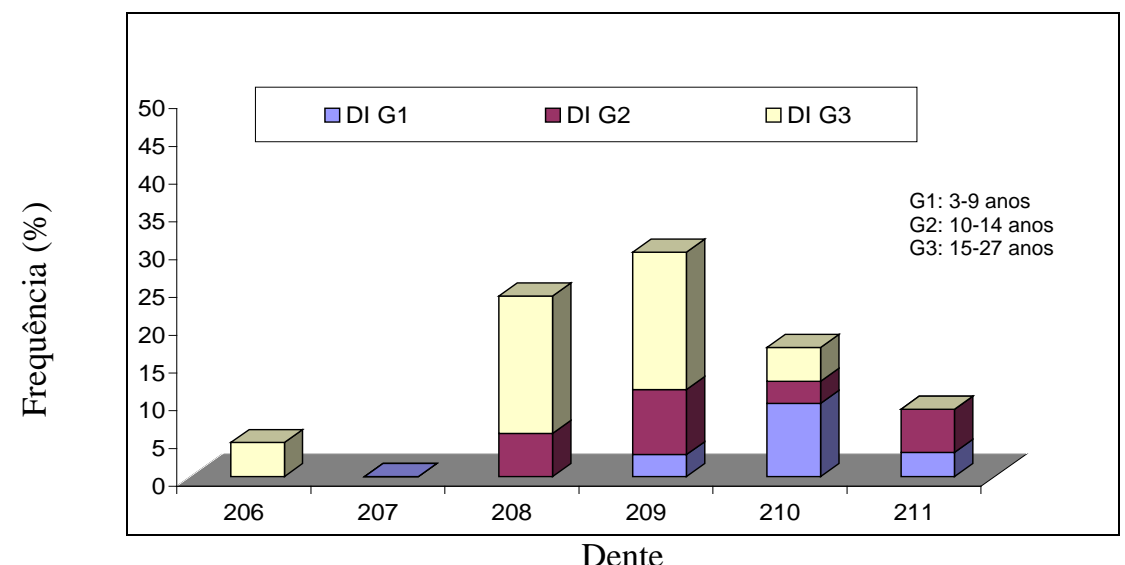

Figura 2. Frequência de doença infundibular (DI) nos dentes da maxila lado esquerdo, em equinos.

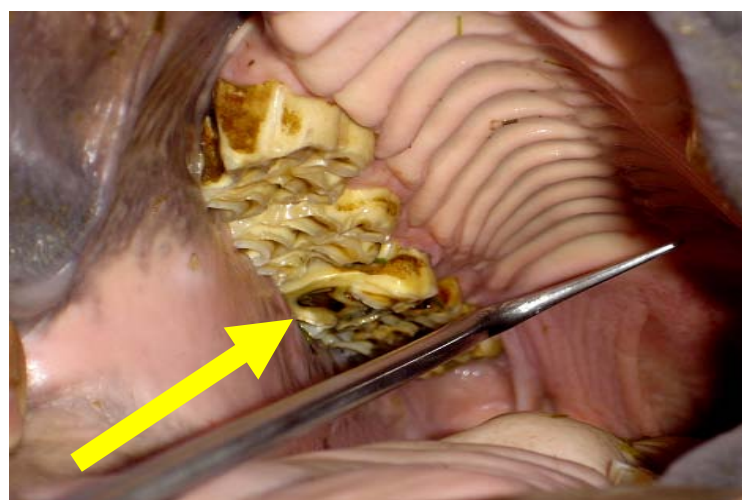

Figura 3. Doença infundibular no dente 108 em equino.

Além da idade, outros fatores estão envolvidos na ocorrência de DI, como o desequilíbrio na alimentação, devido ao fornecimento de alimento concentrado, além do volumoso. A redução da proporção de alimento volumoso interfere na limpeza fisiológica dos dentes, pois, quando o animal mastiga fibras vegetais, ocorre a produção de saliva. A salivação e a ação mecânica do alimento fibroso auxiliam na remoção de partículas remanescentes de alimento aderido aos dentes, prevenindo o depósito de resíduos alimentares e, consequentemente, a proliferação de bactérias no local (Baker e Easley, 2005). 
Pode-se inferir que, nos animais avaliados, o manejo alimentar alterado e a ausência de avaliação dentária periódica nos equinos contribuíram para a ocorrência de disfunções fisiológicas e anatômicas durante o desenvolvimento do tecido dentário, tornando-os susceptíveis à DI. Com a oferta de concentrado na dieta, sugere-se que o mecanismo de prevenção de deposição de alimento nos dentes pela ação da saliva e do alimento fibroso, aliado à presença de hipoplasia do cemento, tenha ficado prejudicado, favorecendo a manifestação de DI.

Verificou-se que 58 (66\%) dos animais apresentavam SM e 57 (65\%), gancho. Observou-se correlação positiva entre SM e ocorrências de ganchos $(r=0,26, \mathrm{P}=0,016)$ e correlação positiva entre SM e ganchos rostrais maxilares (106 e 206) e mandibulares (306 e 406) $(r=0,25, P=0,016)$. Ao avaliar-se a relação somente entre SM e a ocorrência de ganchos rostrais maxilares, observou-se correlação positiva $(\mathrm{r}=0,24, \mathrm{P}=0,02)$, demonstrando a predominância da SM em animais que apresentaram ganchos rostrais (Tab. 1). Verificou-se que animais com ganchos nos pré- molares maxilares apresentaram 2,8 vezes mais chance de manifestar sobremordida (IC 95\%= 1,1 A 7,1).

Ainda não está explicado se os ganchos são formados em consequência da sobremordida ou se a ordem cronológica do surgimento destas alterações apresenta-se invertida. Acredita-se que uma alimentação com proporção elevada de ração concentrada oferecida aos animais deste estudo estimula a movimentação vertical da mandíbula, o que leva à alteração da forma de desgaste dos dentes. Além disso, a ração concentrada e a forragem são fornecidas, para esses animais, em um nível acima do solo, o que pode provocar mudanças dos movimentos rostrocaudais da mandíbula, diminuindo os rostrais e acentuando os caudais. Em consequência dessas variações, é possível ocorrer alteração da distribuição de forças durante o ciclo mastigatório, levando à formação dos ganchos, conforme mencionaram Pagliosa et al. (2006). Devido à barreira física criada pelos ganchos, restringindo a excursão rostrocaudal da mandíbula, pode ter surgido o posicionamento de sobremordida nestes equinos.

Tabela 1. Valores de correlação (r) e de probabilidade (P) entre sobremordida e ganchos

\begin{tabular}{llll}
\hline & Ganchos & $\mathrm{R}$ & $\mathrm{P}$ \\
\hline \multirow{3}{*}{ Sobremordida } & Rostrais maxilares e mandibulares & 0,25 & 0,016 \\
& Rostrais maxilares & 0,24 & 0,02 \\
& Total de ganchos & 0,26 & 0,016 \\
\hline
\end{tabular}

A partir dos resultados, pode-se inferir que houve influência do manejo alimentar sobre a ocorrência das afecções dentárias discutidas. Uma dieta equilibrada em relação às proporções de concentrado e forragem de alta qualidade é muito importante para reduzir as chances de ocorrência de alterações de desgaste dentário e de afecções, como as avaliadas neste estudo. Observou-se que a oferta de ração concentrada e a consequente redução na proporção de forragem tornaram os animais mais susceptíveis à ocorrência de DI, como descrito também por Crabill e Schumacher (1998). Associado a essa alteração da dieta, o confinamento dos animais também favoreceu a ocorrência de ganchos, com consequente manifestação de SM.

\section{CONCLUSÕES}

A presença de doença infundibular teve influência da idade. Os equinos que apresentam ganchos estão predispostos a manifestar sobremordida.

\section{REFERÊNCIAS BIBLIOGRÁFICAS}

BAKER, G.J.; EASLEY, J. (Eds). Equine dentistry. Philadelphia: Elsevier, 2005. 353p.

BAKER, G.J. Some aspects of equine dental decay. Equine Vet. J., v.6, p.127-130, 1974.

CRABILL, M.R.; SCHUMACHER, J. Pathophysiology of acquired dental diseases of the horse. Vet. Clin. N. Am.: Equine Pract., v.14, p.291-307, 1998. 
DIXON, P.M.; TREMAINE, W.H.; PICKLES, K. et al., Equine dental disease. Part. 1: a longterm study of 400 cases: disorders of incisors, canine, and first premolar teeth. Equine Vet. J., v.31, p.369-377, 1999.

DIXON, P.M. The gross, histological, and ultrastructural anatomy of equine teeth and their relationship to disease. In: ANNUAL CONVENTION OF THE AAEP, 48., 2002, Orlando. Proceedings... Orlando, 2002. p.421437.

DIXON, P.M.; DACRE, I. A review of equine dental disorders. Vet. J., v.169, p.165-187, 2005.

GORDON, J.B. Dental physical examination. Vet. Clin. N. Am.: Equine Pract., v.14, p.247257, 1998.

JOHNSON, T.J.; PORTER, C.M. Infundibular caries. In: AMERICAN ASSOCIATION OF EQUINE PRACTITICIONERS, FOCUS MEETING, 2006, Indianapolis. Proceedings... Indianapolis, 2006. Disponível em: $<$ http://www.ivis.org $>$. Acessado em: 26 ago. 2007.
KILIC, S.; DIXON, P.M.; KEMPSON, S.A. A light microscopic and ultrastructural examination of calcified dental tissues of horses. 4. Cement an amelocemental junction. Equine Vet. J., v.29, p.213-219, 1997.

OMURA, C.M. Mensuração da sobressaliência incisal e dos diastemas em potros (Equus caballus). 2003. 67f. Dissertação (Mestrado) Faculdade de Medicina Veterinária e Zootecnia, Universidade de São Paulo, São Paulo.

PAGLIOSA, G.M.; ALVES, G.E.S.; FALEIROS, R.R. et al. Influência das pontas excessivas de esmalte dentário na digestibilidade e nutrientes de dietas de equinos. Arq. Bras. Med. Vet. Zootec., v.58, p.94-98, 2006.

RALSTON, S.L. Feeding dentally challenged horses. Clin. Tech. Equine. Pract., v.4, p.117119, 2005.

SPIERS, V.C. The alimentary tract. In: SPIERS, V.C., WRIGLEY, R.H. Clinical examination of horses. Philadelphia: Saunders, 1997. p.261-298. 